\title{
Deformation behaviour of the compressed square ring of 7075 aluminium alloy
}

\author{
F. $\mathrm{Li}^{1 *}$, G. N. Chu ${ }^{2}$, J. F. $\operatorname{Lin}^{3}$, S. L. Feng ${ }^{3}$ \\ ${ }^{1}$ College of Materials Science and Engineering, Harbin University of Science and Technology, Harbin 150040, China \\ ${ }^{2}$ School of Naval Architecture, Harbin Institute of Technology at Weihai, Weihai 264209, China \\ ${ }^{3}$ School of Material Science and Engineering, Harbin Institute of Technology, Harbin 150001, China
}

Received 20 August 2009, received in revised form 9 April 2010, accepted 9 April 2010

\begin{abstract}
Numerical simulation and experiment were employed to analyse the compression of square ring of 7075 aluminium alloy. The effect of deformation condition on metal flow behaviour was analysed during square ring compression. The results indicate that deformation uniformity increases obviously as height-diameter ratio increases and the metal flow outwards along radial direction increases for the same. Consequently, the complex degree of metal flow behaviour is enhanced. Through experiment verification, the results coincide well with the simulated results, which provides theoretical references for the investigation of pre-fabricated billet technology.
\end{abstract}

K e y w o r d s: 7075 aluminium alloy, square ring, compression, numerical simulation

\section{Introduction}

Upsetting is one of the basic plastic forming processings; it is also a main preforming method during complex forging process. As a result, it is useful and can provide a theoretical basis for process design of complex forging by studying the characteristics of deformation in detail $[1,2]$.

The deformation characteristics of cylindrical and ring upsetting belongs to compressive deformation and many scholars have conducted widespread study on this area [3-6]. For example, by applying specific external constraints the flow behaviour can be changed in process of cylinder compression [7]. Zok analysed three traditional measures for reducing the drum trend during cylinder compression. The result shows that it is most effective to reduce the drum trend when compressing cylinder among a ring, and can also improve the deformation homogeneity greatly. This is coincided well with the actual production [8]. Due to different contact conditions in billet and tools, there are significant differences between ring compression and cylinder compression. By simulation study the compression deformation of ring through the inter-plate shows that, under the same condition of the friction factor and the degree of deformation, the external diameter of ring shows the character of convex single drum, the deformation characteristics of internal diameter have three forms with the ratio of height to diameter increasing. Friction significantly affects the distribution of divert surface during the process of ring compressive deformation. By in-depth analysing the process of compressive deformation of the ring, it reveals the ring's shape changes using different lubricants, and then determines the friction coefficient using different lubricants. Ultrasonic can significantly reduce the deformation resistance of metals, it can be seen that, at room temperature, internal diameter reduces when compared to traditional ring deformation with height decreasing by using ultrasonic. Even compared with the hot ring compression, the reduction of internal diameter using ultrasonic is still slightly larger.

Above all, present studies are limited to the simple cylinder and ring compressions. The special geometrical shape billet compression deformation behaviour is rarely reported. As a result, in this paper the process of the square ring compression is set as an example,

*Corresponding author: tel./fax: +86-451-86392510; e-mail address: hitlif@126.com 


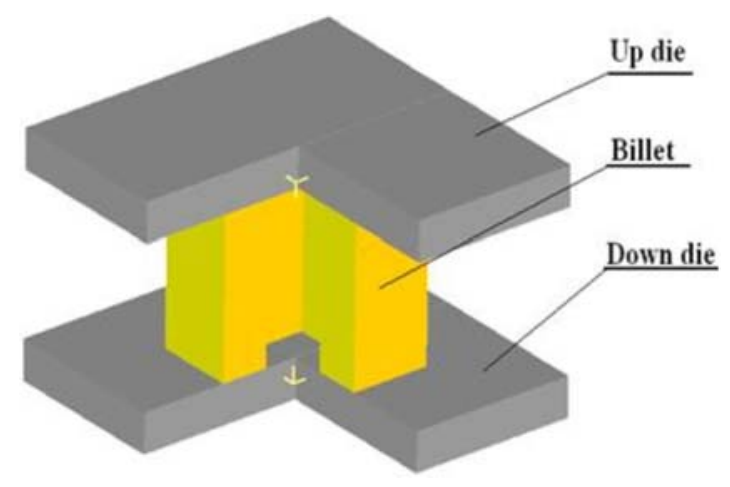

Fig. 1. Finite element model (3/4).

the study researches the influence of process conditions on metal deformation by numerical simulation and experiment.

\section{Research program}

\subsection{Finite element model}

Finite element software DEFORM ${ }^{\mathrm{TM}} \mathrm{D}_{-}$D was used to simulate the forming process. In order to reduce the number of unit and improve the computing speed and time, billet's $1 / 4$ was used as simulation study object. Tetrahedral units of the billet were used, in the process of calculation they were redrawn at anytime in case of mesh distortion to ensure the accuracy and astringency. The points of symmetry plane were imposed constraint to make sure the normal velocity of the symmetric plane was zero. Figure 1 shows the finite element model.

The die deformation was neglected in the process of simulation, and its material properties were of the rigid body. In simulation, billet corresponding to 7075 aluminium alloy was used as an ideal rigid-plastic material model. The coefficient of friction between billet and container was 0.3 , which was determined by the relationship between inner diameter and height of ring compression experiment.

\subsection{Simulation program}

Two square rings were studied to show the deformation behaviour. The external side lengths of both square rings were $24 \mathrm{~mm}$, and the internal side lengths were $8 \mathrm{~mm}$ and $10 \mathrm{~mm}$. The process of square ring's deformation can be affected by many factors, in order to facilitate research, three values of height: $10 \mathrm{~mm}$, $15 \mathrm{~mm}$ and $20 \mathrm{~mm}$ were used. All other parameter values remained unchanged; the forming speed of compressive deformation is $1 \mathrm{~mm} \mathrm{~s}^{-1}$.

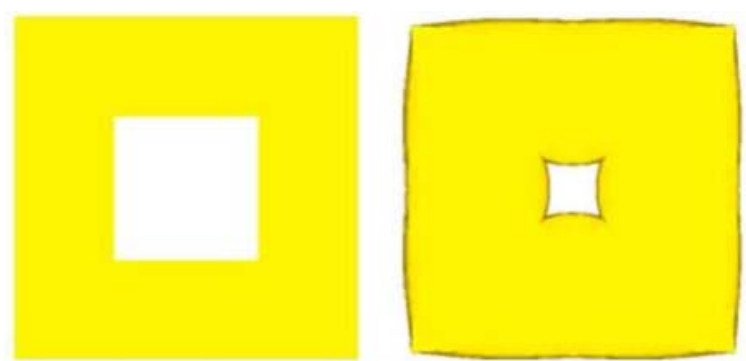

(a)

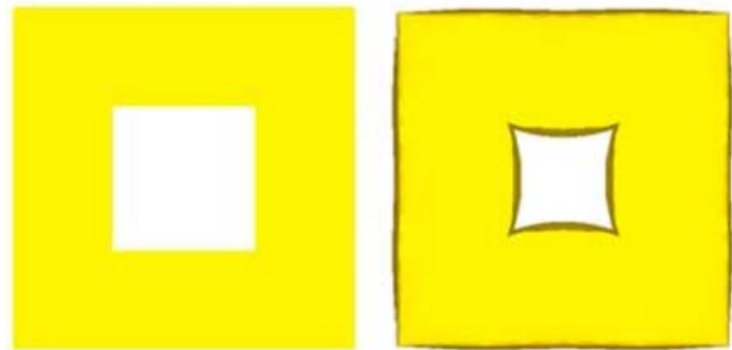

(b)

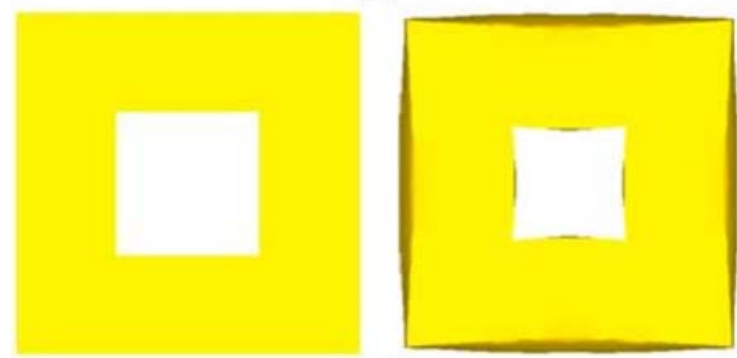

(c)

Fig. 2. Comparison of compression deformation of square rings with different height: (a) $10 \mathrm{~mm}$, (b) $15 \mathrm{~mm}$, (c) $20 \mathrm{~mm}$.

\section{Results discussion and analysis}

\subsection{Deformation characteristics}

Figure 2 shows the comparison of square ring compression for different heights. The square ring's external side length was $24 \mathrm{~mm}$ and the internal side length was $10 \mathrm{~mm}$.

Figure 2a shows that after compression deformation double drum deformation appears outside. On the contrary, single drum deformation happens inside of square ring. With the height decreasing, the double drum deformation outside becomes more obvious, and the hole diameter becomes smaller.

It can be seen that in the process of compression, the metal deformation trend flowing along the radial is more significant. When height increased to $15 \mathrm{~mm}$, as shown in Fig. 2b, the deformation characteristic was similar with the former, but the hole radial reducing rate decreased significantly. As a result, metal flow inward along the radius direction decreased significantly. 


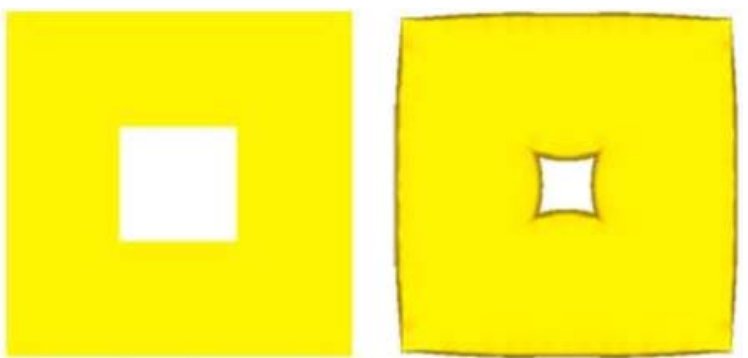

(a)

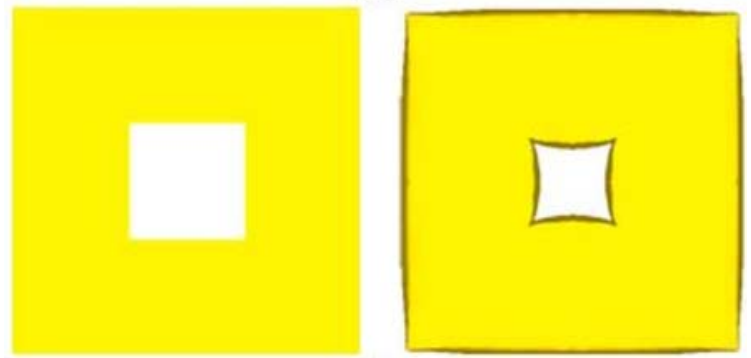

(b)

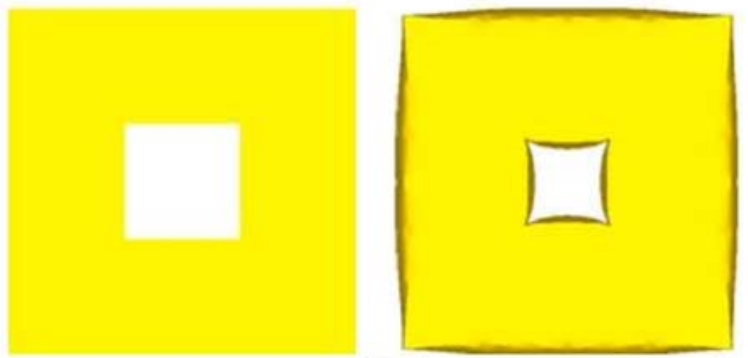

(c)

Fig. 3. Comparison of compression deformation with different height: (a) $10 \mathrm{~mm}$, (b) $15 \mathrm{~mm}$, (c) $20 \mathrm{~mm}$.

When height increased to $20 \mathrm{~mm}$, with the stroke increasing, square ring's outside showed external convex single drum deformation. It can be seen in Fig. 2c that the hole radial reducing rate decreases further, however, metal flow outward along the radius direction increases significantly.

It can be seen that when the square ring's external and internal side lengths were $24 \mathrm{~mm}$ and $10 \mathrm{~mm}$, respectively, with height increasing, the square ring's compression deformation characteristics changes from external convex double drum into external convex single drum, metal flow outward along the radius increases significantly, but the hole radial reducing rate decreases significantly.

Figure 3 shows the comparison of the square ring's compression deformation with different height, the square ring's external and internal side lengths were $24 \mathrm{~mm}$ and $8 \mathrm{~mm}$, respectively.

It can be seen in Fig. 3a that after compression, both the inside and outside of the square ring show external convex single drum deformation. As stroke increases, the square ring's external side drum deform- ation becomes more obvious, but the whole radial reducing rate decreases significantly. That is to say the deformation distribution in the process of compression along the radial direction is relatively uniform. When the height increased to $15 \mathrm{~mm}$ as shown in Fig. 3b, the square ring's external side single drum deformation became more obvious, but internal hole shows single and small drum deformation. When stroke increases, the square ring's external convex single drum deformation becomes more obvious, but the whole radial reducing rate decreases relatively. It can be seen that metal flow inward along the radius direction decreases relatively.

When the height increased to $20 \mathrm{~mm}$, it can be seen in Fig. 3c that the square ring's external convex single drum deformation became more obvious, and at the same time the hole radial reducing rate decreased further, metal deformation behaviour along the radius concentrated relatively on the outside region.

It can be concluded that when the square ring's external and internal side lengths were $24 \mathrm{~mm}$ and $8 \mathrm{~mm}$, respectively, with ring's height increasing, the square ring's external convex single drum deformation becomes more obvious, simultaneously the deformation of metal flowing outward along the radial is more significant, and the hole radial reducing rate decreases further.

\subsection{Equivalent stress analysis}

Figure 4 shows the square ring's equivalent stress distribution in different comparison process, which external and internal side lengths were $24 \mathrm{~mm}$ and $10 \mathrm{~mm}$, respectively.

It can be seen from Fig. 4a that when the stroke is 10 steps, the largest equivalent stress locates in all the upper and lower outside edges and in the middle zone of the hole, consequently plastic deformation occurs in these zones. While the equivalent stress near the hole is small, plastic deformation occurs later than other zones. With the stroke increasing, the largest equivalent stress locates in the outside of the square ring, the middle of the hole, and the transverse plane near the hole, the smallest equivalent stress locates in the upper and lower edge outside the square ring. It can be seen that with the stroke increasing, the equivalent stress of outer side increases from two sides into the centre, and the equivalent stress of inner side mainly converges on the middle part and gradually increases.

When the square ring's height is $15 \mathrm{~mm}$, as shown in Fig. 4b, and the stroke is 15 steps, the largest equivalent stress locates in the upper and lower edge outside the square ring and the middle of the hole, the smallest equivalent stress locates in the transverse plane near the hole. When the stroke increases to 35 steps, the largest equivalent stress locates in the 


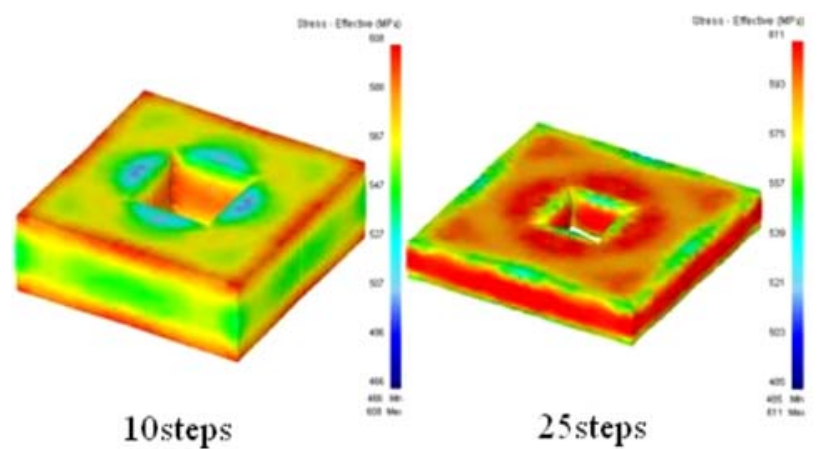

(a)

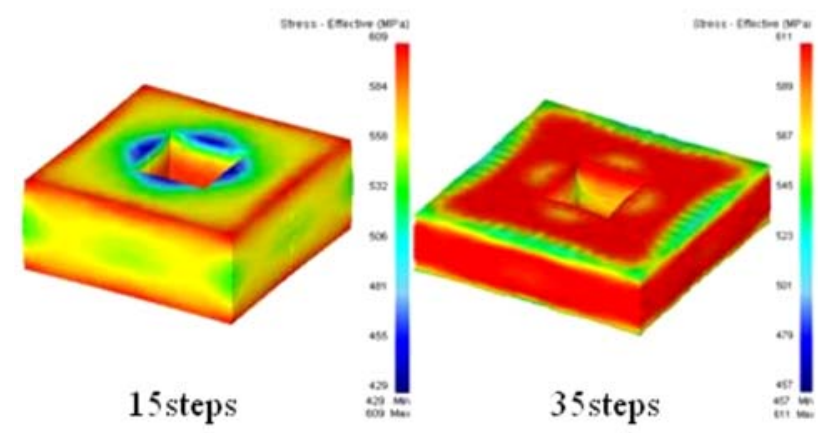

(b)

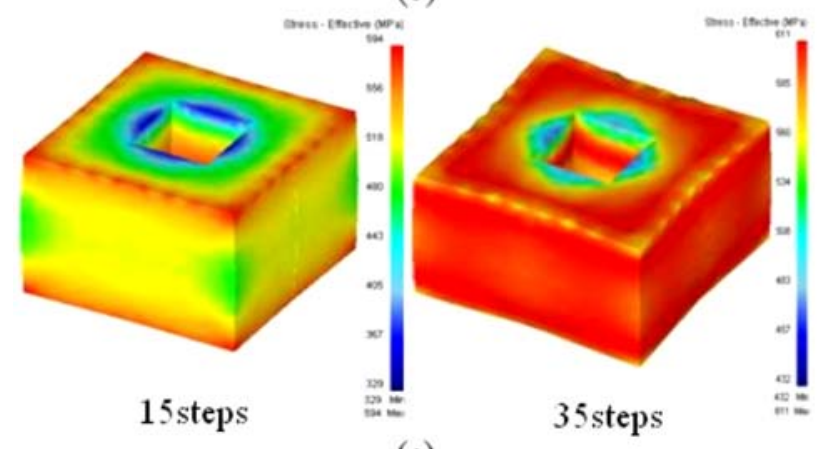

(c)

Fig. 4. Comparison of equivalent stress distribution rule: (a) $10 \mathrm{~mm}$, (b) $15 \mathrm{~mm}$, (c) $20 \mathrm{~mm}$.

middle of the outside square ring and the most region of the upper and lower transverse plane except the hole, the smallest equivalent stress locates in the upper and lower edge outside the square ring. By contrast, with the stroke increasing, the equivalent stress of outer side transfers from two sides into the centre and is well distributional, the metal deformation trend in the upper and lower transverse plane is obvious, while the deformation trend in the middle of the inner side is small. When the height of the billet increases to $20 \mathrm{~mm}$, as shown in Fig. 4c, and the stroke is 15 steps, the distribution of equivalent stress is more or less the same as the former, but the maximum magnitude reduces to $594 \mathrm{MPa}$, the distribution of smaller numerical region is the same as the former, but the minimum magnitude reduces to $329 \mathrm{MPa}$. When the reduction increases to 35 steps, the largest equival-

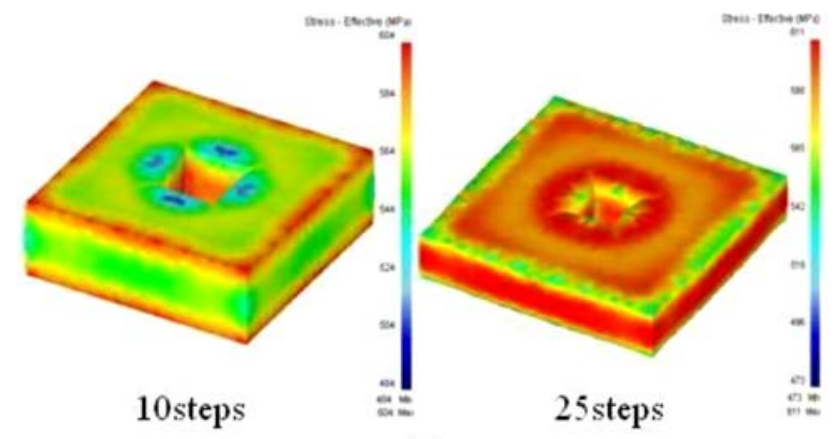

(a)

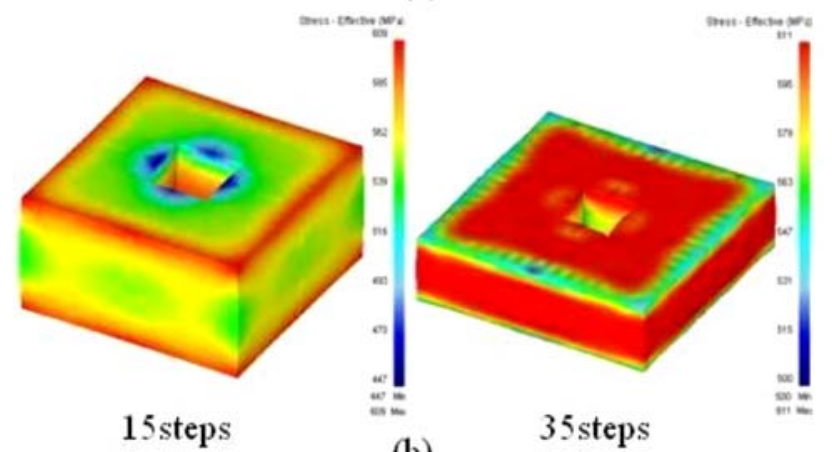

(b)

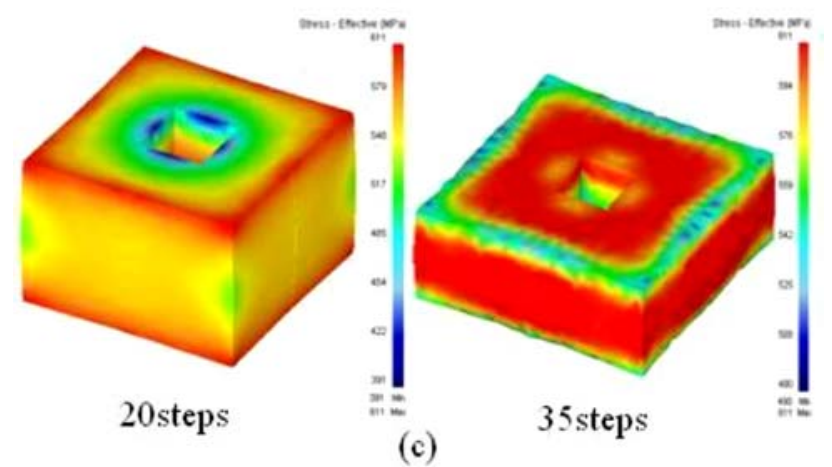

Fig. 5. Comparison of equivalent stress distribution rule: (a) $10 \mathrm{~mm}$, (b) $15 \mathrm{~mm}$, (c) $20 \mathrm{~mm}$.

ent stress locates in the vast majority region except the edge, therefore, at this time plastic deformation has taken place in most majority region, however, the outer seamed edge and the inner middle region are difficult to be deformed.

Figure 5 shows the square ring's equivalent stress distribution in different compression process, which external side length was $24 \mathrm{~mm}$, and the hole side length was $8 \mathrm{~mm}$.

It can be seen in Fig. 5a that when the billet's height is $10 \mathrm{~mm}$ and the stroke is 10 steps, the largest equivalent stress locates in the edge outside and middle of the hole, the smallest equivalent stress locates in the transverse plane near the hole. When the reduction increases to 25 steps, the maximum equivalent stress locates in the outer side, middle of the hole and the transverse plane near the hole, plastic deform- 


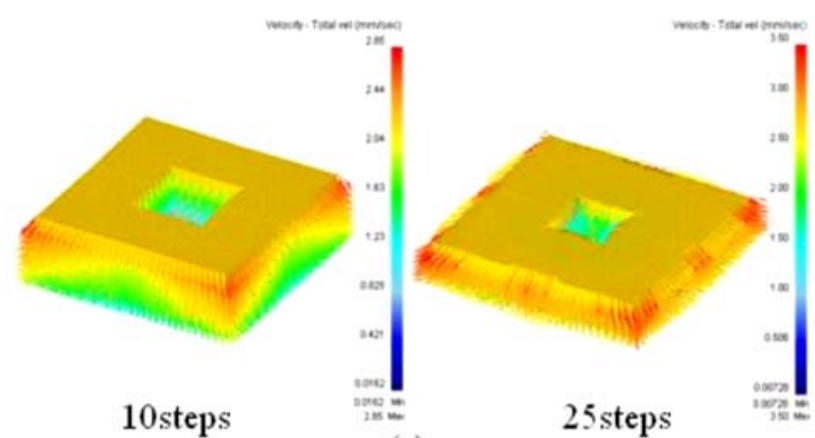

(a)

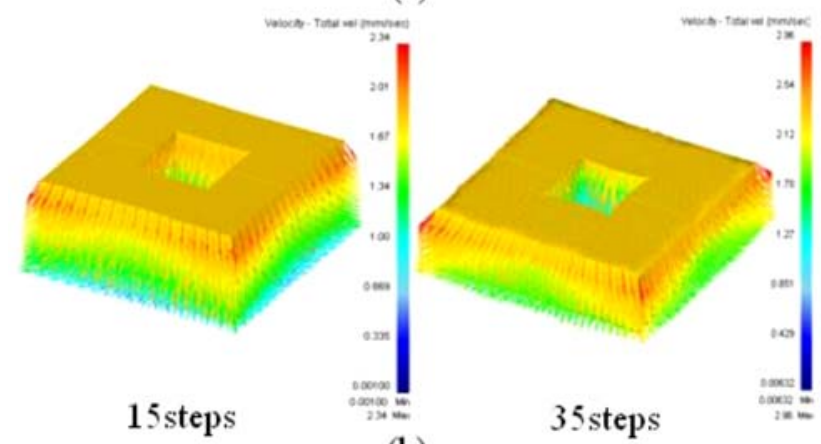

(b)

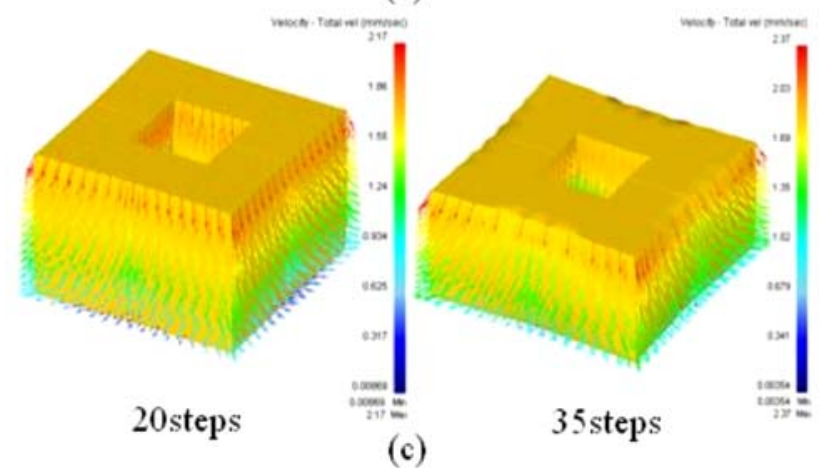

(c)

Fig. 6. Comparison of velocity field distribution rule: (a) $10 \mathrm{~mm}$, (b) $15 \mathrm{~mm}$, (c) $20 \mathrm{~mm}$.

ation has taken place in these areas. The maximum equivalent stress locates in the upper and lower edge outside the square ring, it can be seen that the distribution trends of equivalent stress are: as the stroke increases, the outer side transfers from the two sides to the centre. On the contrary the inner side mainly concentrates at the centre and increases with stroke increasing.

\subsection{Metal flow behaviour}

When the billet's height is $15 \mathrm{~mm}$, as shown in Fig. 5b, the stroke is 15 steps, the equivalent stress distribution trend is similar to the former, just the magnitude of equivalent stress increases a little. It can be seen by comparison that the equivalent stress distribution trends are: as the stroke increases, the outer side transfer from the two sides into the centre, metal deformation trend is significant in the transverse plane, but the deformation trend is weak in the inner middle region. When the height increases to $20 \mathrm{~mm}$, as shown in Fig. 5c, the equivalent stress distribution rule trends are: the outer two sides gradually extend to the whole region, tip occurs in plastic deformation obviously, however, in the middle of the inner side occurs plastic deformation weakly.

Figure 6 shows the square ring's velocity vector field distribution of different compression process, their external side length is $24 \mathrm{~mm}$, and the hole side length is $10 \mathrm{~mm}$.

It can be seen from Fig. 6 that when the reduction is 25 steps, the flow speed of metal in outer side gradually reduces along height direction, and the same trend of metal flow speed appears inside metal. For the same plane, the flow speed of inside metal is significantly lower than that of the outer side. When the reduction increases to 25 steps, the fastest metal flow region concentrates in the outside area, and the whole velocity field becomes well distributed, and the angle between the directions of compression significantly increases, and as increasing in compression, metal's velocity along the radius increases. Figure $6 \mathrm{~b}, \mathrm{c}$ shows the comparison of velocity field distribution, the heights of billet are $15 \mathrm{~mm}$ and $20 \mathrm{~mm}$, respectively. When the stroke is small, just as Fig. 6b,c shows, the distribution rule of the velocity vector is similar to the former, and on the same plane the inner and the outer velocity become relatively uniform, but as the stroke increases, there is a little difference in the distribution rule of the velocity vector compared with the height $10 \mathrm{~mm}$, however, flow speed also decreases along height direction.

Figure 7 shows the comparison of the square ring's velocity field, its external side length was $24 \mathrm{~mm}$, and hole side length was $10 \mathrm{~mm}$.

It can be seen in Fig. 7a that when the reduction is 10 steps the fastest speed of metal flow locates in the top outside of the square ring, and speed decreases from top to down. The inside speed distribution is similar to that outside. When the stroke increases to 25 steps, the fastest metal flow region is the outer side, and the outer side distribution of velocity vectors becomes relatively uniform, the angle between the direction and compression significantly becomes larger, but on the same plane the inside amount is smaller than the outside amount.

Figure $7 \mathrm{~b}, \mathrm{c}$ shows the comparison of the square ring's velocity field distribution whose length is $15 \mathrm{~mm}$ and $20 \mathrm{~mm}$, respectively. When the stroke is small, the distribution of the velocity vector is the same as the one which height is $10 \mathrm{~mm}$. As the reduction increases, the speed of billet with height $15 \mathrm{~mm}$ decreases from top to down. However, the distribution of billet with height $20 \mathrm{~mm}$ is uniform and the velocity vector number is small. That is to say the trend of metal flow is relatively slow. 


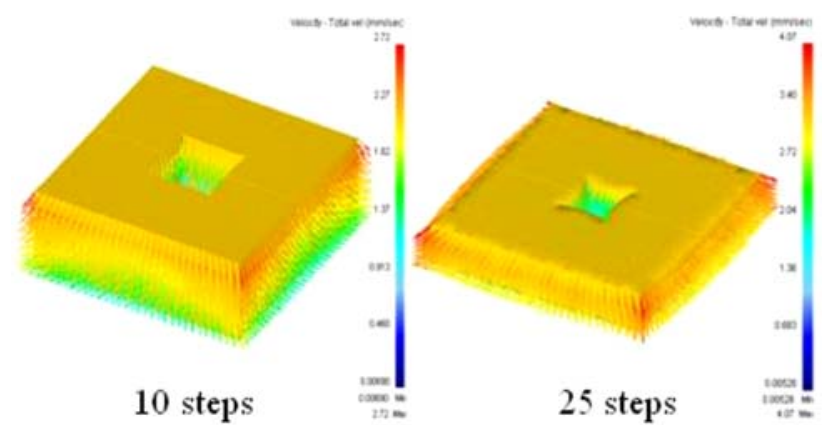

(a)

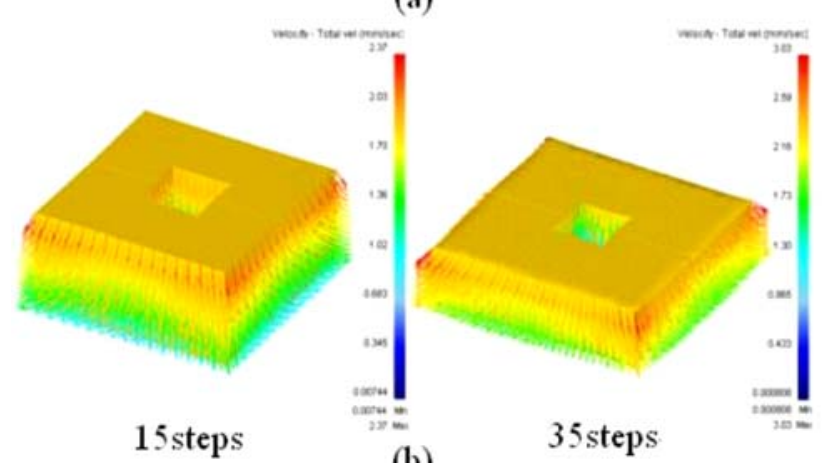

(b)

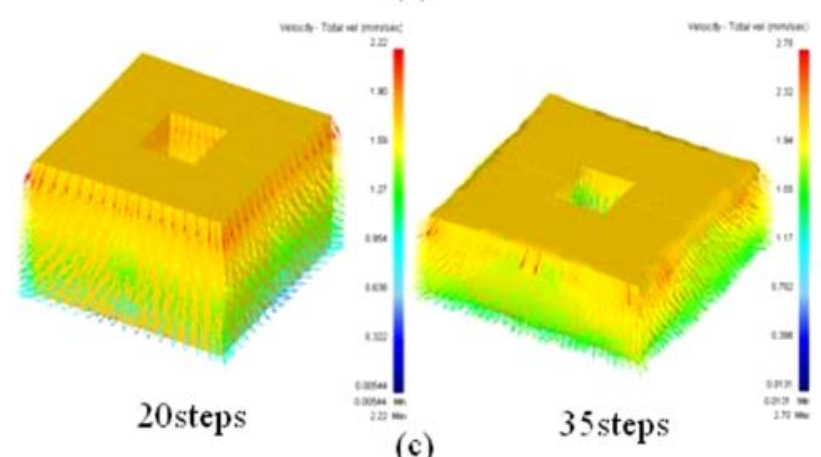

(c)

Fig. 7. Comparison of velocity field distribution: $10 \mathrm{~mm}$, (b) $15 \mathrm{~mm}$, (c) $20 \mathrm{~mm}$.

\section{Experiment}

Experiment was performed on the $1000 \mathrm{KN}$ hydraulic universal testing machine; the displacement, velocity, etc. were controlled by console desk. The relative compression value of the square ring was observed by dial test indicator, other conditions were the same as the simulation.

Figure 8 shows the comparison of the square ring's compression results, its outer side length was $24 \mathrm{~mm}$, and inner side length was $8 \mathrm{~mm}$ and $10 \mathrm{~mm}$.

It can be seen that as the stroke increases, inner side and outer side compression deformation trend is relatively uniform, and terminal face change is not obvious, direction of the flow of metal is the same as the direction of the compression. With the reduction increasing, the square ring's inner side shows significant external convex single drum deformation, when
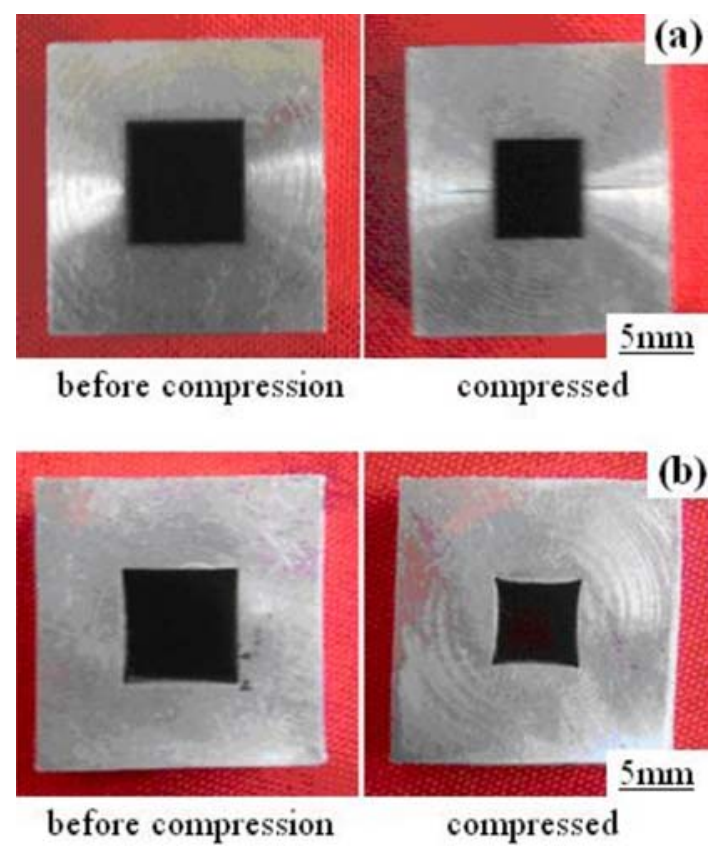

Fig. 8. Comparison of the square ring's compression: (a) inner side length was $10 \mathrm{~mm}$, (b) inner side length was $8 \mathrm{~mm}$.

the outer side length is $24 \mathrm{~mm}$ and inner side length is $8 \mathrm{~mm}$, their outer side also shows external convex deformation. Compared with the square ring whose inner side length is $10 \mathrm{~mm}$, there is obvious change in terminal face, that is to say metal deformation along the radial relatively increased.

\section{Conclusions}

1. During square ring compression, as the ratio of height to diameter increases, metal flowing inward along the radius direction reduces gradually, while metal flowing outward increases significantly.

2. For a certain degree of deformation, the complexity of metal flow increases with increasing the billet's height.

3. During square ring compression, deformation decreases along axial direction, but increases along radial direction as the ratio of height to diameter increases. That means it is harder to deform along axial direction, and the billet's upper and lower terminal face shape changes more obviously.

\section{Acknowledgements}

This paper was financially supported by Foundation of Heilongjiang Educational Committee (11541042) and Harbin Science and Technology Innovative Talents (2010RFQXG021). The authors would like to take this opportunity to express their sincere appreciation. 


\section{References}

[1] ROBInSON, T.-OU, H.-ARMSTRONG, C. G.: J Mater Proc Technol, 153-154, 2004, p. 54.

[2] TROJANOVA, Z.-LUKAC, P.: Kovove Mater., 2005, 43, p. 73 .

[3] KUGLER, D.-MOON, T. J.: Composites, A33, 2002, p. 507.
[4] HAMZAH, S.-STAHLBERG, U.: J Mater Proc Technol, 84, 1998, p. 25.

[5] KARMAN, T.: Z. Ver. Deutsch. Ing., 55, 1911, p. 1749.

[6] WANG, D. N.: Principles of Metal Forming. Beijing, Machinery Industry Press 1986.

[7] MEINERS, F.-RÖHR, S.-JURGENSEN, R. S.: Advanced Technology of Plasticity, 1, 2002, p. 37.

[8] ZOK, F.-EMBURY, J. D.: J Mater Proc Technol, 8, 1990, p. 77. 